\title{
BEARS (BERKELEY EXPERIMENTS WITH ACCELERATED RADIOACTIVE SPECIES)*
}

\author{
J. Cerny III ${ }^{+}$, F. Guo ${ }^{+}$, R. Joosten ${ }^{+}$, R.M. Larimer ${ }^{+}$, C.M. Lyneis ${ }^{+}, \underline{\text { M.A. McMahan }}{ }^{+\#}$, E.B. Norman ${ }^{+}$, \\ J. O’Neil ${ }^{\&}$, J. Powell ${ }^{+}$, M. Rowe ${ }^{+}$, H. VanBrocklin ${ }^{\star}$, D. Wutte ${ }^{+}$, Z.Q. Xie ${ }^{+}$, X.J. Xu ${ }^{+}$, LBNL, $^{2}$ \\ Berkeley, CA \\ P. Haustein, BNL, Upton, NY
}

\begin{abstract}
The BEARS project at Lawrence Berkeley National Laboratory is developing the capability for some proton-rich radioactive beams using a coupledcyclotron method. Initial studies have focused on ${ }^{11} \mathrm{C}$ and ${ }^{14} \mathrm{O}$ and the first physics experiment is complete using ${ }^{11} \mathrm{C}$ in batch mode. Ionization efficiencies have been measured as high as $11 \%$ for ${ }^{11} \mathrm{C}^{+4}$. The total efficiency for ionization and acceleration is approximately $1 \%$ and total beam intensities of $1 * 10^{8}$ have been observed. Upon completion of the transfer line, beam intensities of $2 * 10^{8}$ are expected for ${ }^{11} \mathrm{C}$ and $5 * 10^{6}$ for ${ }^{14} \mathrm{O}$.
\end{abstract}

\section{INTRODUCTION}

There is at the present time extensive world-wide activity in the development and construction of radioactive ion beam (RIB) facilities of various types. The availability of beams of unstable nuclei offers exciting new opportunities for research into nuclear structure and nuclear astrophysics. Construction of the Isotope Separator On-Line (ISOL) is the next construction priority of the U.S. Nuclear Science Long Range Plan.

Much R\&D must be done before ISOL can be realised, and completion of the project is years in the future. In the meantime, limited RIB capability can be achieved in a variety of ways. Berkeley Experiments with Accelerated Radioactive Species (BEARS) is an initiative to develop limited RIB capability at the Lawrence Berkeley National Laboratory (LBNL).

The basic concept for Phase I of the BEARS project involves coupling the Biomedical Isotope Facility (BIF) in Bldg. 56 at LBNL with the 88-Inch Cyclotron through a 300 meter transfer line, as shown in the site map of Figure 1. BIF [1] is a commercial $10 \mathrm{MeV}$ fixed energy $\mathrm{H}_{2}$ cyclotron used for making isotopes for Positron Emission Tomography. It is well suited for making light neutron-deficient radioactive beams using gas targets. The 88-Inch Cyclotron facility, shown schematically in Figure 2, produces both heavy-ion and light-ion beams for nuclear physics studies. It's two Electron Cyclotron Resonance (ECR) ion sources, the LBL-ECR and the state-of-the-art Advanced ECR, the AECR-U, efficiently produce highly charged ions. As will be shown, the combination of the efficiency of an ECR source with the mass resolution of a cyclotron creates a powerful secondary accelerator for radioactive ions.

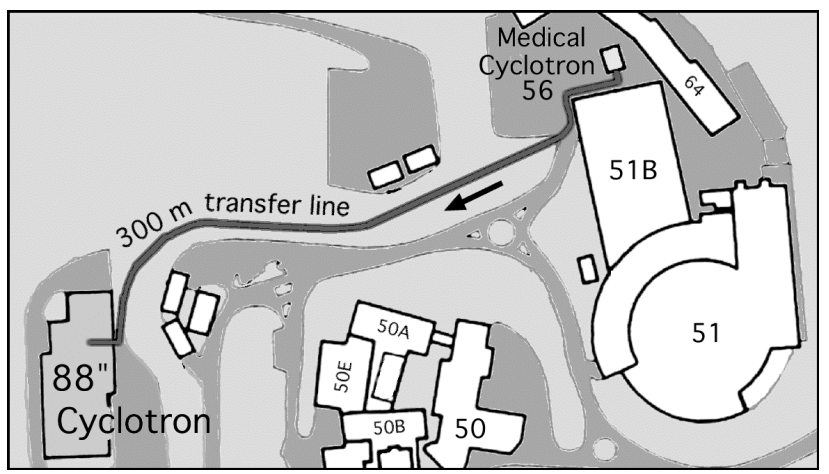

Figure 1. Site map of transfer line between two cyclotrons

\section{PRODUCTION AND TRANSPORT}

The initial BEARS development has focused on the production of ${ }^{11} \mathrm{C}$ and ${ }^{14} \mathrm{O}$, with half-lives of 20 minutes and $70 \mathrm{sec}$, respectively. Initial attempts were made to produce the species in solid targets and transport them on small aerosol clusters for direct injection into the ECR source. The method is broadly applicable to many isotopes; however, it failed to transport significant amounts of ${ }^{11} \mathrm{C}$ or ${ }^{14} \mathrm{O}$. This was traced to the majority of the activity forming gaseous compounds and thus not attaching to the aerosol clusters. Much higher transportation efficiencies are obtained when the ${ }^{11} \mathrm{C}$ and ${ }^{14} \mathrm{O}$ is made in bombardments of protons on a $\mathrm{N}_{2}$ gas target, in the reactions ${ }^{14} \mathrm{~N}\left(\mathrm{p},{ }^{4} \mathrm{He}\right){ }^{11} \mathrm{C}$ and ${ }^{14} \mathrm{~N}(\mathrm{p}, \mathrm{n}){ }^{14} \mathrm{O}$, respectively. When a trace amount of $\mathrm{O}_{2}$ is added to the target gas, the radioactive carbon is predominantly in _the form of ${ }^{11} \mathrm{CO}_{2}$. The $\mathrm{CO}_{2}$ is swept out of the target with a He-jet and transported through a narrow capillary to one of the ECR sources.

\footnotetext{
This work supported by USDOE, Division of Nuclear Physics, under contracts DE-AC03-76SF00098 at LBNL and DE-AC0298CH10886 at BNL

+ Nuclear Science Division

"Email: p_mcmahan@lbl.gov

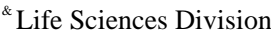




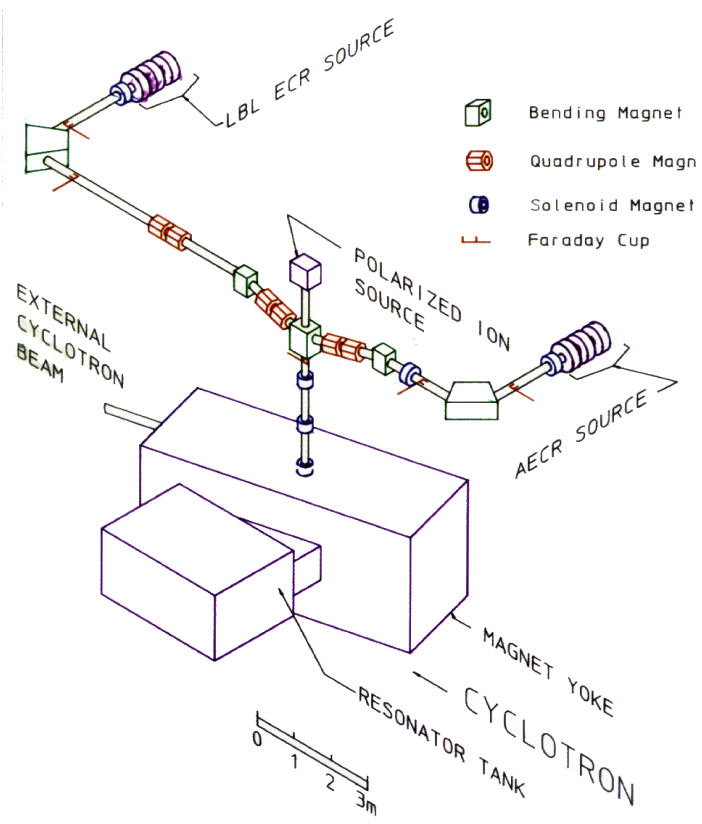

Figure 2. The 88-Inch Cyclotron and its ECR ion sources.

. Once there, the radioactive $\mathrm{CO}_{2}$ is trapped in liquid- $\mathrm{N}_{2}$ and the helium support gas pumped away. This method allows simple, maximum-yield production at the BIF and is easily adapted to use in the AECR-U.

\section{IONIZATION}

The first development phase of the BEARS project took place solely at the 88-Inch Cyclotron, with protons from one ECR source accelerated to $10 \mathrm{MeV}$ to mock up the BIF. The activity was transported to the second ECR source through a $300 \mathrm{~m}$ capillary where studies were made of the efficiencies and hold-up times for ionization and extraction of the radioactive ions. The best efficiency results were obtained using the AECR$\mathrm{U}$, a high performance source built in 1990 and upgraded in 1996. This ion source is well optimized for the production of highly charged ions, with a strong magnetic field configuration which can support the hotter plasma which is essential to the production of highly charged ions. [2] It is one of the few ECR sources that incorporate all of the advances in technology of ECR sources made in recent years multiple-frequency plasma heating, good plasma chamber surface coating with high yield of cold secondary electrons and high magnetic mirror fields. [3] It has produced many record charge states and beam intensities.

Efficiencies for ionization of the radioactive species were obtained by measuring the activity at the cryogenic trap before emptying into the source, and then the build up of activity on a Faraday cup after the 90 degree analyzing magnet at the exit of the source. Corrections were made for half-life and detector efficiencies. Ionization efficiencies using the LBL-ECR and AECR-U sources are shown in Table 1 for several charge states of ${ }^{11} \mathrm{C}$ and ${ }^{14} \mathrm{O}$. Efficiencies as high as $11 \%$ were obtained for ${ }^{11} \mathrm{C}^{+4}$. There is room for improvement, however, as can be seen in the measured efficiencies of stable ${ }^{12} \mathrm{C}$ and ${ }^{16} \mathrm{O}$ charge states using a calibrated $\mathrm{CO}_{2}$ leak. Here efficiencies of $23.4 \%$ were obtained for ${ }^{12} \mathrm{C}^{+4}$ and $33 \%$ for ${ }^{16} \mathrm{O}^{+6}$.

It is important for efficient RIB production that the time the radioactive species spends in the source, the "hold-up" time is short in comparison to its lifetime. Source hold-up times in the AECR-U have been measured for stable $\mathrm{CO}_{2}$ and found to be of the order of 5-7 sec. When the decay of the activity is measured for ${ }^{11} \mathrm{C}$ and ${ }^{14} \mathrm{O}$, two components are seen in the decay curve. The fast component is on the order of 20-30 sec for both species. The slow component is on the order of $360 \mathrm{sec}$ for the ${ }^{11} \mathrm{C}$. If one could shorten the hold-up times in the source to be nearer to that of stable carbon and oxygen, the ionization efficiencies should approach those of the stable species. This is particularly important for the $70 \mathrm{sec}$ isotope ${ }^{14} \mathrm{O}$, for which an order of magnitude improvement could be made. Once the transfer line is complete, these studies will be pursued.

Table 1: Ionization efficiencies and hold-up times for radioactive and stable $\mathrm{CO}_{2}$ in AECR-U

\begin{tabular}{|c|c|c|c|c|c|}
\hline Ion & ECR & \multicolumn{2}{|c|}{ AECR-U } & \multicolumn{2}{c|}{ Stable CO O $_{2}$ Leak } \\
\hline C & $\%$ & $\%$ & $\tau_{\text {fast }}(\mathbf{s e c})$ & $\%$ & $\tau_{\text {fast }}(\mathbf{s e c})$ \\
\hline $1+$ & 1.1 & & & & \\
\hline $2+$ & 0.7 & & & & \\
\hline $3+$ & 0.4 & 4 & & & \\
\hline $4+$ & 0.9 & 11 & 24 & 23.4 & 5.6 \\
\hline $5+$ & 0.1 & 4 & & 15.4 & \\
\hline $6+$ & & 2 & & & \\
\hline $\mathbf{O}$ & & & & & \\
\hline $3+$ & 0.4 & & & & \\
\hline $4+$ & 0.4 & & & & \\
\hline $5+$ & 0.4 & & & 12.5 & \\
\hline $6+$ & & 3.6 & & 33 & 7.1 \\
\hline $7+$ & & 1.2 & $20-30$ & 7.44 & \\
\hline $8+$ & \multicolumn{7}{|l}{0.4} & & & \\
\hline
\end{tabular}

\section{ACCELERATION}

In order to tune a low-intensity radioactive beam through the cyclotron, one tunes a stable beam close to the same charge to mass ratio $(\mathrm{q} / \mathrm{m})$. Table 2 lists the isotopic masses and the RF frequency at a typical energy for the two sets of analog beams: $\left[{ }^{11} \mathrm{C},{ }^{11} \mathrm{~B}\right.$ and $\left.{ }^{22} \mathrm{Ne}\right]$ and $\left[{ }^{14} \mathrm{O},{ }^{14} \mathrm{~N}\right.$, and $\left.{ }^{28} \mathrm{Si}\right]$. Also shown is the 


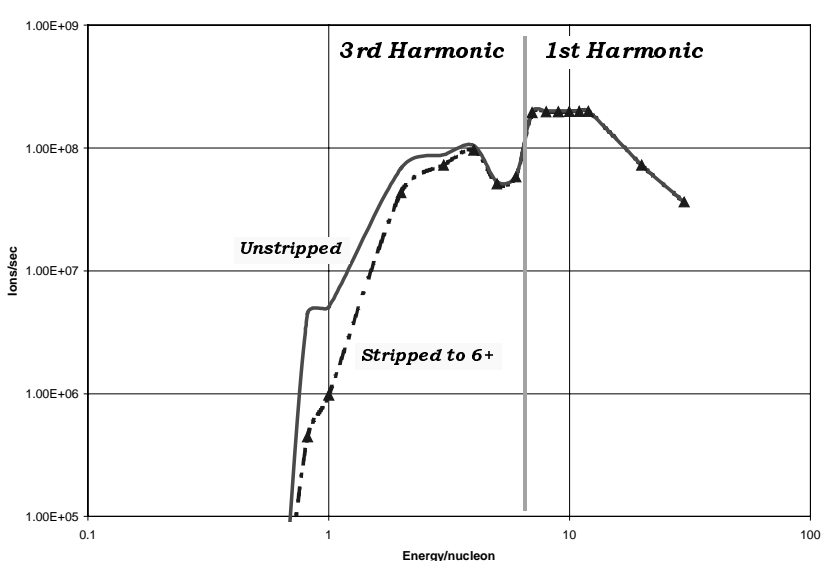

Figure 3. Predicted ${ }^{11} \mathrm{C}$ intensities as a function of energy/nucleon. The solid curve is the maximum unstripped intensity using the most advantageous charge state at each energy using the ionization efficiencies of Table 3. The dashed curve is the intensity after stripping to +6 .

frequency difference between the analog beam and its radioactive partner, a quantity that is directly related to the mass difference. The frequency resolution of the 88-Inch Cyclotron is approximately $2 \mathrm{kHz}$. Thus one can see that ${ }^{11} \mathrm{C}$ and ${ }^{22} \mathrm{Ne}$ can be easily separated by tuning the frequency, but ${ }^{11} \mathrm{C}$ and ${ }^{11} \mathrm{~B}$ cannot be separated. Thus the ${ }^{11} \mathrm{~B}$, rather than being a convenient analog beam for tuning, becomes instead an annoying contaminant.

In the first tests to accelerate ${ }^{11} \mathrm{C}$, the initial ${ }^{11} \mathrm{~B}$ intensity was measured to be a factor of 100 less than that of the ${ }^{11} \mathrm{C}$. However, in subsequent runs it was found that the ${ }^{11} \mathrm{~B}$ intensity was very high, a factor of 1000 greater than that of the ${ }^{11} \mathrm{C}$. Between the two runs, boron was run in the ion source and it remains a low level contaminant for months. Recent measurements have shown that the boron contamination has dropped off considerably. Another source of ${ }^{11} \mathrm{~B}$ contamination naturally builds up during the course of an ${ }^{11} \mathrm{C}$ run, due to the decay of ${ }^{11} \mathrm{C} \rightarrow{ }^{11} \mathrm{~B}$ inside the ion source.

Table 2: Analog Beams of ${ }^{11} \mathrm{C}$ and ${ }^{14} \mathrm{O}$

\begin{tabular}{|c|l|l|l|l|}
\hline Ion & $\begin{array}{c}\text { Energy } \\
\mathbf{M e V}\end{array}$ & $\begin{array}{c}\text { Mass } \\
\text { (amu) }\end{array}$ & $\begin{array}{c}\text { Frequency } \\
\text { (MHz) }\end{array}$ & $\begin{array}{c}\Delta \text { Freq } \\
\text { (kHz) }\end{array}$ \\
\hline${ }^{11} \mathrm{C}^{+4}$ & 125 & 11.011433 & 7.5222 & - \\
\hline${ }^{11} \mathrm{~B}^{+4}$ & 125 & 11.0093054 & 7.5236 & 1.4 \\
\hline${ }^{22} \mathrm{Ne}^{+4}$ & 250 & 21.9913831 & 7.5327 & 10.5 \\
\hline${ }^{14} \mathrm{O}^{+6}$ & 140 & 14.008595 & 7.0656 & - \\
\hline${ }^{14} \mathrm{~N}^{+6}$ & 140 & 14.003074 & 7.0684 & 2.7 \\
\hline${ }^{28} \mathrm{Si}^{+12}$ & 280 & 27.976927 & 7.0756 & 10.0 \\
\hline
\end{tabular}

The method developed to set up the cyclotron for a $\mathrm{RIB}$ run using ${ }^{11} \mathrm{C}$ and eliminate the ${ }^{11} \mathrm{~B}$ background is a multi-step process:

i) Tune injection line, cyclotron and beam line using ${ }^{22} \mathrm{Ne}^{+8}$ at the same energy/nucleon

ii) Switch to ${ }^{11} \mathrm{~B}^{+4}$ frequency and look for contamination; fine tune cyclotron and beam line

iii) Put a thin stripper foil in beam line before one of the final bending magnets

iv) Strip ${ }^{11} \mathrm{~B}$ from $+4 \rightarrow+5$ and retune line

v) Scale beam line magnets to ${ }^{11} \mathrm{C}^{+6}$

vi) Put ${ }^{11} \mathrm{C}$ into ion source and fine tune source and beam line magnets for maximum intensity

Using this procedure, a first physics experiment was done using the ${ }^{11} \mathrm{C}$ beam, in spite of the fact that the transfer line to the BIF was not yet complete. The ${ }^{11} \mathrm{C}$ activity was carried from the BIF by truck, then cryotrapped and injected into the AECR-U, giving 30 minutes of beam every hour for several short runs. In the best case, a clean ${ }^{11} \mathrm{C}$ beam intensity of $1 * 10^{8}$ ions/sec was achieved for a short while, and $5 * 10^{7}$ ions/sec typically. It is expected that upon completion of the transfer line, beam intensities of $\approx 2 * 10^{8}$ ions $/ \mathrm{sec}$ will be typical with an optimal choice of beam energies. Intensities for ${ }^{14} \mathrm{O}$ are expected to be $\approx 5 * 10^{6}$ ions/sec.

The above method relies on the fact that at these energies the probability to fully strip an ion in a thin foil is greater than 99\%. At lower energies, the probability to fully strip the carbon ions will decrease. In addition, the transmission of the cyclotron decreases in certain regions of magnetic field and when running in higher harmonics. In Figure 3, these factors plus source ionization efficiencies are folded together to calculate a predicted ${ }^{11} \mathrm{C}$ beam intensity as a function of energy/nucleon. At energies near $1 \mathrm{MeV} /$ nucleon, the region of interest for nuclear astrophysics intensities are significantly lower - approximately $5 * 10^{6}$ for unstripped beams and $5 * 10^{5}$ for clean ${ }^{11} \mathrm{C}^{+6}$ beams. Even at these intensities, the expected production of BEARS is comparable to that of other facilities such as HRIBF at Oak Ridge and CYCLONE at Louvain-laNeuve. At energies applicable for nuclear structure and reaction studies, production from BEARS should rival the best of the Cyclone beams.

\section{REFERENCES}

[1] VanBrocklin, H.F. and O'Neil, J.P., in Applications of Accelerators in Research and Industry, ed by Duggan, J.L. and Morgan, I.L., New York: AIP Press, 1997, pp. 1329-1332

[2] Xie, Z.Q. and Lyneis, C.M., proceedings of the $13^{\text {th }}$ Int'l Workshop on ECR Ion Sources, College Station, TX, Feb. 1997, p. 16

[3] Xie, Z.Q., Rev. Sci. Instrm. 69. 625 (1998). 